\title{
Fricción, (re)concentración y afianzamiento conservador tras las elecciones de 2018 en Paraguay
}

\author{
Juan Mario Solís Delgadillo (México* ${ }^{*}$ \\ Sarah Patricia Cerna Villagra (México) ${ }^{* *}$
}

\section{Resumen}

Las elecciones generales de 2018 mantuvieron en el poder al Partido Colorado, una de las pocas maquinarias electorales que se mantienen en la región, su capacidad de ganar elecciones y la homogeneidad del voto a su favor dan muestra de ello. Sin embargo, este último proceso electoral también ha supuesto una fractura al interior del partido. El artículo revela, a través de datos comparados e indicadores, la enorme fuerza de este partido y busca responder qué ha permitido a la Asociación Nacional Republicana mantenerse en el poder. El argumento central para atender a dicho cuestionamiento es que la ANR es el único partido con una estructura lo suficientemente robusta como para movilizar a una gran cantidad de electores, aún y a pesar de las divisiones internas que ha experimentado en los últimos cinco años.

\section{Palabras clave}

Elecciones; Partidos Políticos; Cambio Político; Partido Colorado; Mario Abdo Benítez; Horacio Cartes; Paraguay.

Fechaderecepción: septiembrede 2018

- Fechadeaprobación: octubrede 2018

\section{Cómo citar este artículo}

Solís Delgadillo, Juan Mario y Cerna Villagra, Sarah Patricia. (2019). Fricción, (re)concentración y afianzamiento conservador tras las elecciones de 2018 en Paraguay. Estudios Políticos (Universidad de Antioquia), 54, pp. 259-285. http:// doi.org/10.17533/udea.espo.n54a13

\footnotetext{
* Politólogo. Magíster y doctor en Estudios Latinoamericanos. Profesor investigador de tiempo completo y miembro del Cuerpo Académico Reforma del Estado y Derechos Humanos en la Universidad Autónoma de San Luis Potosí, México. Miembro del Sistema Nacional de Investigadores (SIN) del Consejo Nacional de Ciencia y Tecnología (Conacyt), nivel II. Correo electrónico: juan. solis@uaslp.mx

** Licenciada en Ciencias Políticas. Magíster en Ciencia Política. Doctora en Estado Derecho y Gobernanza Global. Catedrática del Consejo Nacional de Ciencia y Tecnología (Conacyt) adscrita al Centro de Estudios Sociológicos de El Colegio de México. Correo electrónico: scerna@colmex.mx
} 


\title{
Friction, (Re)Concentration and Conservative Consolidation after the 2018 Elections in Paraguay
}

\begin{abstract}
The 2018 general elections kept the Colorado Party in power, one of the few electoral machineries that remain in the region, due to their ability to win elections and the homogeneity of the vote in their favor. However, this last electoral process has also caused a fracture within the party. The article reveals, through comparative data and indicators, the great strength of this party and seeks to answer the question: What has allowed the National Republican Association to stay in power? The central argument for addressing this question is that the NRA is the only party with a structure robust enough to mobilize a large number of voters, despite the internal divisions it has experienced in the last five years.
\end{abstract}

\section{Keywords}

Elections; Political Parties; Political Change; Colorado Party; Mario Abdo Benítez; Horacio Cartes; Paraguay. 
Fricción, (re)concentración y afianzamiento conservador tras las elecciones de 2018...

\section{Introducción}

Las elecciones paraguayas suelen tener, en términos académicos y mediáticos, un tratamiento modesto. En el plano de la investigación social, solo hasta los años más recientes ha sido posible encontrar trabajos que aborden de manera más sistematizada los resultados electorales en ese país (Alcántara y Tagina, 2013; Solís y Cerna, 2013; 2016; Cerna y Solís, 2017; 2018; Duarte, 2012; Došek, Pérez y Duarte, 2016; Alcántara, Tagina y Buquet, 2018). Esta nueva literatura ha procurado analizar los procesos electorales de Paraguay desde múltiples enfoques y en distintas arenas de competencia.

Los trabajos de Juan Mario Solís, Sarah Patricia Cerna (2013; 2016), por ejemplo, han puesto el énfasis en la mirada diacrónica de las elecciones generales y cómo se ha distribuido el poder a partir de calcular diferentes indicadores de partidos y sistemas de partidos; al mismo tiempo, han explorado en la arena subnacional, con la cual han logrado capturar la medida del índice de nacionalización de los partidos paraguayos y por qué ha resultado difícil derrotar a la Asociación Nacional Republicana (ANR). Otros autores como Tomáš Došek, Marcos Pérez y Liliana Duarte (2016) han puesto su mirada en lo que ocurre en las elecciones en el ámbito municipal, aunque concentrándose únicamente en una muestra parcial de territorios, por lo que existe toda una veta por explorar de manera más consistente. Rocío Duarte (2013; 2012), por su parte, aborda los procesos electorales en la clave de las coyunturas críticas que se han presentado en las elecciones de 2008 y 2013. En cualquier caso, la disposición de información útil y bien documentada sobre las elecciones en aquel país sudamericano es hoy en día mucho más accesible que en años anteriores. ${ }^{1}$

A casi tres décadas de la transición hacia la democracia, se puede decir que los procesos electorales son más la regla que la excepción y que, en ese sentido, Paraguay es una democracia electoral consistente, por lo que se refiere a la regularidad con la que se han celebrado seis elecciones generales desde 1993. Sin embargo, y a pesar de la formalidad electoral que se repite cada cinco años desde entonces, Paraguay es catalogado como uno de los

\footnotetext{
${ }^{1}$ Esto obedece, entre otras cosas, a que la Ciencia Política en Paraguay se ha abierto paso, no sin dificultades, y los colegas han logrado conformar la Asociación de Ciencia Política del Paraguay, la cual, además de nuclear a los politólogos del país, ha ordenado los estudios de la disciplina. Esto es por demás interesante porque refleja que el creciente interés por parte de los colegas sobre estos temas tiene una correlación con la edad de la mayoría de ellos, que son hijos de la transición hacia la democracia.
} 
países con mayor inestabilidad política en la región a causa de los recurrentes acontecimientos disruptivos de su vida política, cruzada por asesinatos políticos (1999), intentos de golpes de Estado (1996), protesta social (2006, 2017), escándalos de corrupción (2002), salidas anticipadas de los presidentes (1999) o juicios políticos (2012) (Pérez-Liñán, 2009; 2014; Pérez-Liñán y Polga-Hecimovich, 2017; Uharte, 2012; Abente, 2012; Cerna y Solís, 2012; 2017; 2018).

Con esos rasgos como telón de fondo, las elecciones generales de 2018, con las que se renovó la titularidad del Poder Ejecutivo, las dos cámaras legislativas y las gobernaciones departamentales, se presentaron como unos comicios de «disrupción continuista» en los que, como nunca antes - $\mathrm{O}$ al menos no con tanta evidencia- el partido en el gobierno logró su permanencia en el poder, pero con una fractura enorme entre las corrientes internas del nuevo presidente Mario Abdo Benítez (Colorado Añeteté) y el mandatario saliente Horacio Cartes (Honor Colorado) (Pérez Talia, 2018, junio 13; Cerna y Solís, 2018).

Ahora bien, en el contexto del maratón electoral que vive la región entre 2017 y 2019, las pasadas elecciones generales paraguayas se insertan [262] en un contexto que algunos denominan «de giro a la derecha» (Londoño, Bonnefoy y Politi, 2017, diciembre 19; Quintana, 2018, octubre 28; Lissardy, 2017; Núñez, 2018, julio 19); sin embargo, aquí se opta por calificar a este proceso como un viraje al integrismo religioso, con base en la cada vez mayor presencia e influencia de partidos de base religiosa, principalmente evangélicos o pentecostales, que de manera discreta han incursionado en el campo electoral a través de algunos de sus ministros de culto y la estructura social de sus feligresías en crecimiento, las cuales financian, vía sus diezmos, las actividades políticas de estas iglesias. Estos partidos han demostrado tener una importante penetración por sí solos o bien una significativa capacidad de chantaje con relación a los partidos con grandes estructuras, los cuales, en contextos de mayor competitividad, encuentran en estos partidos emergentes una cuota sustancial de votos que puede inclinar la balanza a su favor (Bedinelli, Marcos y Lafuente, 2018, abril 13; Corrales, 2018, enero 19; Lissardy, 2018, abril 17). Algunos ejemplos se pueden observar en las recientes elecciones de Guatemala, Costa Rica, México y Brasil, así como también en el referéndum por la paz celebrado en Colombia en 2016, en el que este tipo de partidos trabajaron intensamente con el uribismo en la campaña del No al proceso de 
paz (Lissardy, 2018, abril 17; Brenes, 2018, febrero 10; AFP, 2018, marzo, 28; Lafuente, 2018, octubre 8; Corona, 2018, julio 12).

Estos partidos de base religiosa han introducido en las agendas electorales latinoamericanas temas como las políticas de «mano dura» en materia de seguridad, su oposición al uso recreativo de la marihuana y la corriente que ha acuñado una supuesta «ideología de género» para desprestigiar al movimiento feminista latinoamericano y expresar su rechazo a temas como el matrimonio igualitario, la interrupción del embarazo o la educación en derechos reproductivos y sexuales (Lissardy, 2018, abril 17; Corrales, 2018, enero 19; Bedinelli, Marcos y Lafuente, 2018, abril 13). En ese sentido, han sido institutos políticos muy habilidosos para pactar alianzas con partidos tanto de izquierda como de derecha, como queda de manifiesto con las históricas alianzas de estas iglesias con el PT brasileño entre 2002 y 2014, con Morena en México en 2018, o ser capaces de postular a sus propios candidatos como Fabricio Alvarado en Costa Rica o Jimmy Morales en Guatemala (Lafuente, 2018, octubre 8; Corona, 2018, julio 12; Brenes, 2018, febrero 10; Lissardy, 2018, abril 17).

En Paraguay, si bien no existe evidencia de la creación de este tipo de partidos, no es menos cierto que varios de los temas que suelen postular han sido recogidos por parte de los dos partidos tradicionales paraguayos que se han distinguido por ser institutos políticos con una fuerte impronta conservadorareligiosa de corte predominantemente católica (La Nación, 2018, febrero 11). En suma, se puede concluir que las elecciones paraguayas y sus protagonistas se alinean parcialmente a la tendencia que han experimentado otros casos de la región en cuanto a la aparición e influencia de nuevos partidos de base religiosa; sin embargo, en lo sustancial, los partidos tradicionales han recogido esta agenda con renovado entusiasmo en un país con un electorado tradicionalmente conservador y en el que este tipo de propuestas suelen recibir buena acogida en el mercado electoral.

El presente artículo da cuenta de este proceloso proceso al prestar atención al contexto en el que se desarrollaron estas elecciones; quiénes fueron sus protagonistas y la oferta que presentaron al electorado; el desarrollo de la campaña en cuanto a su desarrollo y estrategias; los resultados electorales y su comparación diacrónica con las cinco elecciones anteriores; el relevamiento de indicadores electorales, como el número efectivo de partidos para cada tipo de elección, la concentración, la competitividad, la volatilidad y la 
nacionalización de partidos; finalmente, se presenta lo que aquí se entiende como escenarios plausibles en el futuro a corto y mediano plazo.

\section{Contexto previo a las elecciones}

\subsection{Los intentos reeleccionistas de Cartes y Lugo: la quema del Congreso Nacional}

En marzo de 2017 el Congreso Nacional de Paraguay ardió en medio de un clima de crispación política entre defensores y detractores de los intentos releccionistas de Horacio Cartes y Fernando Lugo. El clima político paraguayo «ardió en llamas» y una expresión de ello fue la quema de las oficinas del Senado por parte de manifestantes disconformes con los intentos de un bloque de senadores de cambiar de manera express el reglamento interno de la Cámara para eliminar atribuciones del presidente de este cuerpo legislativo y, al mismo tiempo, realizar cambios en la Constitución Nacional sin convocar a una Asamblea Constituyente, y de esta manera modificar el artículo 229 que prohíbe la reelección presidencial (Cerna, 2017, abril 3).

La figura de la reelección presidencial en este país sudamericano, desde [264 ] la transición a la democracia y la creación e implementación de la Carta Magna de 1992, ha sido un tema polémico y complejo para los actores políticos y la sociedad paraguaya en general, especialmente por el pasado reciente del país, que se ha caracterizado por gobiernos autoritarios, en especial por el régimen no democrático de Alfredo Stroessner (1954-1989). Tanto Nicanor Duarte Frutos en 2007 y Fernando Lugo y Horacio Cartes en 2017 han insertado el tema de la reelección en la agenda pública, generando opiniones en contra y a favor de la modificación de este artículo constitucional. Mientras que en 2007 las movilizaciones en contra de los intentos reeleccionistas de Duarte Frutos abrieron la coyuntura política favorable a la figura outsider del obispo Fernando Lugo, diez años después abrieron una brecha tanto al interior del Partido Colorado como en el Partido Liberal Radical Auténtico (PLRA), así como provocaron una fuerte crispación social que acabó incendiando las oficinas del Congreso Nacional, lo que desató una fuerte represión policial que dejó como saldo decenas de heridos, una veintena de imputados, así como un joven militante del PLRA muerto al interior del directorio de este partido en la capital paraguaya (Alvarenga, 2006, diciembre 31; Díaz, 2011, abril 28, ABC Color, 2018, abril 27). 
En ese escenario es importante destacar a los personajes que a la postre protagonizaron la elección presidencial de 2018, ya que tanto Mario Abdo Benítez (ANR) como Efraín Alegre (PLRA) manifestaron en su momento estar en contra de la reforma planteada por el presidente Cartes con un discurso que criticaba el atropello de las instituciones democráticas por la facción de senadores que intentaron cambiar de manera express el reglamento interno de la Cámara, pero al mismo tiempo alentaron a la ciudadanía a salir a las calles a defender la democracia, mientras azuzaron a sus seguidores a los incidentes que terminaron en el incendio de las oficinas parlamentarias (Carneri, 2017, abril 7).

\subsection{La división interna de la Asociación Nacional Republicana (ANR): Colorado Añeteté y Honor Colorado}

En la campaña de la ANR por las elecciones internas se disputaron dos liderazgos muy diferentes entre sí, que han abierto una escisión difícil de zanjar entre las dos facciones, aún después de la victoria electoral de este partido en las elecciones generales de 2018. Por un lado, está el movimiento Honor Colorado, facción política del expresidente Horacio Cartes, que presentó como pre candidato presidencial a Santiago Peña, un joven tecnócrata que estuvo al frente del Ministerio de Hacienda durante dos años (2015-2017). Peña representaba la figura tecnocrática de los ministros que acompañaron la gestión de Cartes. De pasado liberal, con una formación universitaria en Estados Unidos y experiencia laboral en el Fondo Monetario Internacional, no pudo ceder ante la presión cartista y tuvo que renunciar al PLRA y afiliarse a la ANR en plena convención partidaria para no quedarse sin la cartera que dirigía (Última Hora, 2017, septiembre 5). Por el otro, está la facción del movimiento político Colorado Añeteté, a través del cual contendió el hijo del ex secretario privado de Alfredo Stroessner, Mario Abdo Benítez.

Las principales diferencias entre ambos candidatos se encuentran en sus posturas en torno a: a) la reforma constitucional; b) la reelección presidencial; c) los bonos soberanos; d) el aborto; y e) la unión civil de personas del mismo sexo. Mientras que Santiago Peña se pronunció públicamente a que no está a favor de una reforma constitucional porque la sociedad paraguaya «no está madura para poder debatir a profundidad todos los puntos que se pueden plantear en una reforma», Peña señalaba sí estar de acuerdo con la reelección vía enmienda constitucional por ser la forma «más democrática» para que la ciudadanía incida en dicha decisión. Con respecto a temas económicos, Peña 
consideraba que los bonos soberanos son útiles para el desarrollo económico del país. En cuanto a la agenda más polémica de los derechos civiles, este pre candidato colorado señalaba que aún no tenía definida su postura en torno al aborto, pero que estaba «abierto al debate». Respecto al matrimonio igualitario, el político cartista sí consideraba que las personas «deberían tener la posibilidad de decidir con quién unirse de manera civil» (Telefuturo, 2017, mayo 10).

Por su parte, sobre estos mismos temas, Mario Abdo afirmó estar de acuerdo con una reforma y que en caso de ganar llamaría a una asamblea constituyente en el primer año de mandato. Con respecto al debate de la reelección presidencial, manifestó estar a favor, vía reforma constitucional, pero no en el periodo inmediato al del presidente que la implemente. En el ámbito económico, apuntaba estar a favor de los bonos soberanos, pero de manera moderada y con una implementación discreta. Finalmente, respecto al aborto y el matrimonio igualitario, el hijo del exsecretario de Stroessner afirmaba enfáticamente no estar de acuerdo con la legalización de la interrupción del embarazo y que, además, es una «persona católica, apostólica, romana que respeta lo que dice la Biblia, por ello, no estoy a favor del matrimonio igualitario» (Telefuturo, 2017, mayo 10).

\section{Candidatos y programas}

\subsection{El heredero del ala militante del coloradismo: Mario Abdo Benítez}

La familia de Mario Abdo Benítez pertenece al ala militante de la ANR, que en la convención colorada de 1987 se presentó como el Cuatrinomio de Oro, compuesto por Sabino Augusto Montanaro, Adán Godoy Jiménez, Mario Abdo Benítez ( $p$ ) y Eugenio Jacquet, cuyo objetivo era purgar la ANR y el Gobierno de todos los traidores al stronismo. Mientras que, del otro lado, los tradicionalistas bajo el liderazgo de Juan Ramón Chávez y Luis María Argaña buscaban reformas para el partido. Dichas facciones se identificaban con lo que en la literatura se denomina los duros del régimen — los militantesy los blandos — los tradicionalistas-. El padre del actual presidente, Mario Abdo Benítez perteneció durante mucho tiempo al primer anillo político del presidente autoritario Alfredo Stroessner y, en este sentido, durante su campaña las críticas a su figura denominada como «neostronista» fueron constantes desde diversos partidos políticos de oposición (La Nación, 2017, julio 26). 
Al respecto, cabe señalar que Mario Abdo Benítez se identificó en su campaña electoral por apelar a los valores tradicionales que caracterizan a la ANR: la unidad, el patriotismo, la familia, y el militarismo. A modo de ejemplo, entre sus discursos más polémicos, el presidenciable colorado afirmaba que «los hijos de madres solteras deben ir a los cuarteles militares». Aunada a esta frase, en otro mitin político también aseveraba que «el $80 \%$ de los delincuentes provenían de familias disgregadas» por lo que había que proteger el «valor de la familia» para evitar conductas delictivas en la sociedad paraguaya (Última Hora, 2018, marzo 28a). Ambas declaraciones generaron polémicas entre sectores relacionados con la objeción de conciencia, así como en organizaciones de derechos humanos, porque criticaron las creencias implícitas detrás de estas declaraciones, principalmente la cultura militarista que ha dejado en el país deudas históricas de violaciones a derechos humanos (Última Hora, 2018, marzo 28b).

\subsection{La alianza entre liberales y de izquierda: un intento de emular la fórmula victoriosa de 2008}

Los liberales en alianza con diversos partidos y movimientos de izquierda intentaron desafiar al Partido Colorado como lo hicieron en 2008, cuando resultaron victoriosos con la chapa presidencial de Fernando Lugo y Federico Franco. La alianza aglutinó nuevamente al PLRA con movimientos de izquierda como el Frente Guazú, el Partido Revolucionario Febrerista, el Partido Democrático Progresista (PDP), el Partido Encuentro Nacional, Avancemos País y el Partido del Movimiento al Socialismo. La fórmula presidencial de la oposición, la Alianza Ganar — Gran Alianza Nacional Renovada-, postuló al exministro de la era luguista, Efraín Alegre (PLRA), como candidato a presidente y al conductor de radio, Leonardo Rubín (del Frente Guazú), como vicepresidente (La Nación, 2017, diciembre 18).

\section{La campaña electoral, estrategias y debate}

Si algo tienen en común los dos principales candidatos a la presidencia ha sido su conservadurismo, aunque del lado de la Alianza Ganar intentaron abanderarse algunas temáticas de corte progresista de la mano de la fórmula presidencial, Hugo Rubín. Otro rasgo característico de la campaña electoral fue la guerra sucia entre los dos principales contendientes, Mario Abdo Benítez y Efraín Alegre. Mientras que al primero se le acusaba de representar el lado más oscuro del coloradismo por su herencia política, al candidato liberal le endilgaban los malos manejos de la cartera de Obras Públicas y 
Comunicaciones cuando se desempeñó como ministro de Fernando Lugo (La Nación, 2018, febrero 11).

A esta campaña candente también se sumó el presidente en funciones, Horacio Cartes, quien adquirió protagonismo con una serie de frases desafortunadas, como cuando se refirió al candidato liberal diciendo: «Efraín, cuidá tu familia, no te preocupes del Partido Colorado» (ABC Color, 2018, febrero 17). Sobre dicha declaración, Alegre afirmó que se sentía amenazado y que hacía responsable al presidente «por la seguridad de su familia»; agregó que el discurso de Cartes estaba lleno de amenazas y odio, y que él consideraba necesario discutir en una campaña electoral pero que «nadie debe amenazar [a los demás] por sus pensamientos, por defender principios y valores» (Última Hora, 2018, febrero 18).

Los temas centrales de la campaña electoral de Mario Abdo giraron alrededor de la unidad colorada, con lo que claramente estaba apelando al voto duro de la ANR, al tiempo de platear en varias ocasiones «coloradizar al funcionariado público de todo el país» (ABC Color, 2018, marzo 27). Entre sus propuestas de campaña, Abdo señaló las siguientes: a) ampliar la base contributiva y luchar contra la evasión fiscal formalizando la economía;

[268] b) luchar contra la corrupción; c) mejorar la infraestructura del Estado y fortalecer la institucionalidad estatal; d) profesionalizar a la función pública (Última Hora, 2018, abril 15); e) fomentar el control de las fronteras; f) reforma constitucional y emprender una reforma judicial; g) reorganizar la estructura y administración del sistema penitenciario nacional; h) dotar de más presupuesto e infraestructura al sector educativo para alcanzar $7 \%$ de la inversión del PIB, así como también becas de grado y posgrado para fortalecer el capital humano del país; i) priorizar la atención primaria en salud, promoción de la salud comunitaria y la disminución de la mortalidad materno-infantil; j) renegociar el Anexo $\mathrm{C}$ del Tratado de Itaipú, la libre disponibilidad de la energía eléctrica para la venta a otros países, revisión del Acta de Yacyretá y modernización de la Administración Nacional de Electricidad (ANDE) (Última Hora, 2018, abril 3).

Efraín Alegre, por su parte, inició su campaña política recordando a la ciudadanía paraguaya que Mario Abdo Benítez representaba el pasado stronista: «los paraguayos están ante el gran desafío de no volver al pasado y de apostar al futuro» (ABC Color, 2018, enero 22). La campaña electoral de Efraín Alegre se situó alrededor de los siguientes ejes temáticos: a) la salud básica gratuita sin IVA para los medicamentos (Paraguay.com, 2018, febrero 
26); b) la educación de calidad (ABC Color, 2018, abril 5); c) bajar las tarifas de la electricidad a aquellas empresas que generan empleo; d) apostar por un modelo de crecimiento económico equitativo «hacia dentro y hacia abajo»; e) la renegociación de las hidroeléctricas Yacyretá — con Argentina — e Itaipú — con Brasil—; f) terminar con la evasión fiscal, el contrabando y la corrupción; g) aumentar el impuesto al tabaco para destinar recursos a la salud pública; y h) impuesto progresivo a la renta personal (Paraguay.com, 2018, febrero 26).

\section{Análisis de los resultados electorales de las elecciones}

Al entrar de lleno al análisis de los resultados es conveniente hacer notar que, dado el nivel de disputa al interior de la ANR, en este artículo se propone leerlos en dos dimensiones: la primera, a partir de los cánones tradicionales que capturan los resultados de un partido como un todo unificado; y la segunda, sesgando, cuando sea posible por contar con evidencia, el peso de la facción de Honor Colorado como un partido opositor al gobierno. Esto permitirá observar los matices que pasen inadvertidos a los lectores y ajustarse de manera exclusiva a los indicadores en estado puro, al tiempo de creerlo importante, dado grado de enfrentamiento entre las facciones coloradas. Otra consideración es que en esta elección, por primera vez en la historia de la democracia paraguaya, ha habido una proliferación significativa de partidos políticos en disputa por cargos en la arena nacional.

\subsection{La elección presidencial}

Al echar un vistazo a los resultados de la elección presidencial los vaticinios de las encuestas se cumplieron en cuanto al ganador de los comicios, sin embargo, el margen de victoria resultó ser demasiado ajustado frente a la holgada victoria que pronosticaban encuestadoras como Ati Snead y Taca Chase, que por enésima vez resultaron ser un fiasco (Última Hora, 2018, abril 23). De acuerdo con los datos definitivos del Tribunal Superior de Justicia Electoral (TSJE) (Acuerdo y Sentencia 17/2018), la candidatura de Mario Abdo Benítez (ANR) obtuvo el respaldo de 46,42\% de los electores, mientras que su más cercano competidor, Efraín Alegre, logró cosechar 42,74\% de las preferencias válidas. Este resultado ha sido el más ajustado en la serie de elecciones para este cargo desde 1993 (Cerna y Solís, 2018). Sin embargo, otra lectura sobre el resultado y el desempeño de la ANR permite observar que esta ha sido la victoria más sólida en cuanto al porcentaje de votos desde 1998, cuando triunfó Raúl Cubas Grau, dejando incluso atrás el triunfo que solo cinco años atrás obtuvo Horacio Cartes, quien logró 45,8\% de los votos. 
Tabla 1. Resultados históricos de las elecciones presidenciales 1993-2018, en porcentajes.

\begin{tabular}{|l|c|c|c|c|c|c|}
\hline \multicolumn{1}{|c|}{ Partidos } & $\mathbf{1 9 9 3}$ & $\mathbf{1 9 9 8}$ & $\mathbf{2 0 0 3}$ & $\mathbf{2 0 0 8}$ & $\mathbf{2 0 1 3}$ & $\mathbf{2 0 1 8}$ \\
\hline Asociación Nacional Republicana (ANR) & 41,78 & 53,80 & 37,10 & 30,70 & 45,80 & 46,42 \\
\hline Partido Liberal Radical Auténtico (PLRA) & 33,20 & 42,60 & 24,00 & & & \\
\hline Alianza Encuentro Nacional (AEN) & 24,39 & & & & & \\
\hline Alianza Patriótica para el Cambio (APC) & & & & 40,90 & & \\
\hline Alianza Paraguay Alegre (APA) & & & & & 36,90 & \\
\hline Unión Nacional de Ciudadanos Ėticos (Unace) & & & 13,50 & 22,00 & 0,80 & \\
\hline Partido Patria Querida (PPQ) & & 21,30 & 2,40 & 1,10 & \\
\hline Avanza Pais & & & & & 5,90 & \\
\hline Frente Guazú & & & & & 3,30 & \\
\hline Alianza Ganar & & & & & & 42,74 \\
\hline Frente Amplio & & & & & & 0,33 \\
\hline Artistas del Paraguay & & & & & & 0,59 \\
\hline Movimiento Soberania Nacional & & & & & & $\mathbf{0 , 2 8}$ \\
\hline Partido Verde Paraguay & & & & & & 3,23 \\
\hline Movimicnto Reserva Patriótica & & & & & & $\mathbf{0 , 3 6}$ \\
\hline Herederos & & & & & & $\mathbf{0 . 2 3}$ \\
\hline Partido del Movimiento Patriótico Popular & & & & & & $\mathbf{0 . 3 8}$ \\
\hline Unámonos & & & & & & $\mathbf{0 . 2 4}$ \\
\hline Participación & $\mathbf{6 9 , 0 0}$ & $\mathbf{8 0 , 5 0}$ & $\mathbf{6 4 , 3 0}$ & $\mathbf{6 5 , 6 0}$ & $\mathbf{6 8 , 6 0}$ & $\mathbf{6 1 , 2 5}$ \\
\hline
\end{tabular}

Fuente: elaboración propia a partir del TSJE (2018). Las casillas resaltadas en gris en la columna partidos hacen referencia a las alianzas que se han hecho desde 1993.

Estas cifras dan cuenta del crecimiento paulatino de la ANR tras la derrota de 2008 y su capacidad para realinear al electorado paraguayo y aumentar su caudal electoral en los comicios de 2013 y 2018 (Cerna y Solís, 2018). Buena parte de este realineamiento del voto obedece a la vuelta de muchos votantes del Unión Nacional de Ciudadanos Éticos (Unace), otrora el ala más conservadora y militarista del coloradismo, que tras la muerte de su líder, Lino Oviedo, retornaron al redil colorado y que en estas últimas elecciones han recibido con beneplácito la postulación del hijo del secretario privado del dictador Alfredo Stroessner (Solís y Cerna, 2013; 2014).

Otro dato importante es que el PLRA ha crecido muy poco en términos electorales desde 1993, ya que desde entonces sus porcentajes consolidados de votación capturan en promedio al $25 \%$ del electorado, mientras que cuando ha ido en Alianza su desempeño ha oscilado entre 36 y $42 \%$, respectivamente (Solís y Cerna, 2013; 2014; Cerna y Solís, 2018). Pese a la impopularidad del presidente Cartes, la Alianza Ganar no logró convencer al electorado indeciso y no militante, tal vez porque Efraín Alegre ha sido un mal candidato; así 
dan cuenta las dos derrotas consecutivas que ha cosechado en 2013 y 2018, en las que no ha sabido capitalizar a su favor la desazón ante el desgaste de la ANR como un partido asociado a la corrupción. Su figura no logra atraer nuevos electores ni siquiera cuando los adversarios han mostrado notorias precariedades dialécticas, discursivas y argumentativas.

\subsection{La elección legislativa}

En esta arena resulta mucho más claro encontrar las diferencias en cuanto a fuerza electoral efectiva que tienen los diferentes partidos políticos. De acuerdo con los datos del TSJE (Acuerdo y Sentencia 17/2018), la ANR es la agrupación política más poderosa del país al acumular por sí sola 36\% de los sufragios en la elección de diputados y el 30\% correspondiente a la elección al Senado, porcentajes muy holgados con respecto al siguiente partido en preferencia, el PLRA, que en estas mismas elecciones cosechó 16 y $22 \%$ en las elecciones para diputados y senadores, respectivamente.

Al traducir los votos en escaños es evidente que la ANR es una maquinaria electoral muy bien aceitada, a pesar de sus divisiones, porque ha sido capaz de retener sus bastiones, amén de ganar posiciones en distritos históricamente hostiles para los candidatos colorados. De las ochenta bancas a repartir, la ANR ha logrado la mayoría absoluta al conquistar 42 escaños; no obstante, hay que tener en cuenta que los legisladores electos afines al cartismo representan casi la mitad del bloque — veinte- y que, en una lectura más fina, podrían considerarse como una bancada en sí misma, en pie de guerra contra el presidente. Por su parte, el PLRA ha aumentado modestamente el número de bancas a ocupar al pasar de las veintisiete que obtuvo en 2008 y 2013 a las treinta en esta elección; sin embargo, esta mejoría no se aleja de su rango promedio de control de parcelas de poder que es de 34\% (Acuerdo y Sentencia 17/2018; TSJE, 2018).

Lo novedoso en este proceso es que nuevas fuerzas políticas como Hagamos y el Movimiento Cruzada Nacional lograron los votos suficientes para alcanzar escaños tanto en diputados como en senadores, en detrimento de los partidos de izquierda que quedaron fuera de la Cámara baja y de Unace y el PDP en la Cámara alta. Esto es llamativo porque a diferencia del tema que domina las tertulias políticas en el país, que se centra en la confección de las listas cerradas y bloqueadas y no tanto en cuanto a la fórmula para traducir los votos en escaños, estos partidos de reciente creación lograron colar legisladores en condiciones poco favorables cuando las bancas se asignan a 
través de la fórmula D'Hondt, conocida como la menos proporcional de las fórmulas de asignación de escaños, pues favorece a los partidos con mayor captación de votos (Filártiga, 2018; ABC Color, 2017, septiembre 28).

Una sencilla revisión sobre la asignación de las bancas con base en los resultados de esta última elección revela que la conformación de la Cámara de Diputados sería sensiblemente diferente de utilizar la fórmula Hare en lugar de la D'Hondt (véase tabla 2). ${ }^{2}$

Tabla 2. Asignación de escaños en los dieciocho distritos electorales utilizando las fórmulas D'Hondt y Hare, a partir de los resultados electorales de 2018.

\begin{tabular}{|l|c|c|c|c|c|c|c|}
\hline \multicolumn{1}{|c|}{ Distrito } & Escaños & $\begin{array}{c}\text { Asociación } \\
\text { Nacional } \\
\text { Republica } \\
\text { na (ANR) }\end{array}$ & $\begin{array}{c}\text { Partido } \\
\text { Liberal } \\
\text { Radical } \\
\text { Auténtico } \\
\text { (PLRA) }\end{array}$ & Otros & $\begin{array}{c}\text { Fórmula Hare } \\
\text { Asociación } \\
\text { Nacional } \\
\text { Republica } \\
\text { na (ANR) }\end{array}$ & $\begin{array}{c}\text { Partido } \\
\text { Liberal } \\
\text { Radical } \\
\text { Auténtico } \\
\text { (PLRA) }\end{array}$ & Otros \\
\hline Capital & 7 & 4 & 1 & 2 & 2 & 1 & 4 \\
\hline Concepción & 3 & 1 & 2 & & 1 & 2 & \\
\hline San Pedro & 5 & 3 & 2 & & 2 & 2 & \\
\hline Cordillera & 4 & 2 & 2 & & 2 & 2 & \\
\hline Guairá & 3 & 2 & 1 & & 2 & 1 & \\
\hline Caaguazú & 6 & 3 & 3 & & 3 & 3 & \\
\hline Caazapá & 2 & 1 & 1 & & 1 & 1 & \\
\hline Itapúa & 6 & 3 & 3 & & 3 & 2 & 1 \\
\hline Misiones & 2 & 1 & 1 & & 1 & 1 & \\
\hline Paraguari & 4 & 3 & 1 & & 2 & 2 & \\
\hline Alto Paraná & 8 & 4 & 3 & & 3 & 2 & 2 \\
\hline Neembucú & 2 & 1 & 1 & & 1 & 1 & \\
\hline Amambay & 2 & 1 & 1 & & 1 & 1 & \\
\hline Canindeyú & 2 & 1 & 1 & & 1 & 1 & \\
\hline Pdte. Hayes & 2 & 1 & 1 & & 1 & 1 & \\
\hline Alto Paraguay & 1 & 1 & & & 1 & & \\
\hline Boquerón & 1 & 1 & & & 1 & & \\
\hline Central & 20 & 7 & 7 & 6 & 6 & 6 & 8 \\
\hline Totales & $\mathbf{8 0}$ & $\mathbf{4 2}$ & $\mathbf{3 0}$ & $\mathbf{8}$ & $\mathbf{3 6}$ & $\mathbf{2 9}$ & $\mathbf{1 5}$ \\
\hline
\end{tabular}

Fuente: elaboración propia a partir del TSJE (2018).

De la tabla 2 se extrae, por otro lado, que los partidos minoritarios logran alcanzar escaños gracias a la mayor magnitud de los distritos electorales de Central y Capital, lo que supone que son estructuras políticas con anclaje en los territorios más urbanizados, si se excluyen las demarcaciones de Itapúa

\footnotetext{
${ }^{2}$ Para una explicación didáctica y detallada de la traducción de votos en escaños a través de estas fórmulas, véase Luis González (2017).
} 
y Alto Paraná. Por otro lado, al comparar diacrónicamente la composición de la Cámara baja, se encuentra que, salvo los dos partidos tradicionales que han dominado la arena electoral, el sistema de partidos paraguayo ha sido testigo del nacimiento y muerte prematura de una buena cantidad de institutos políticos en poco menos de treinta años de democracia, pero - sobre todoque la concentración de escaños entre las dos principales fuerzas políticas es muy elevada, alcanzando en esta oportunidad $90 \%$ de estas, cifra incluso superior a las de 1993 y 2013. Se llama la atención sobre este aspecto porque Paraguay estaría siendo un caso atípico ya que en la región latinoamericana se observa la tendencia opuesta, lo que por otro lado podría estar indicando que, mientras los grandes partidos tradicionales de la región pierden fuelle, los decanos partidos colorado y liberal de Paraguay gozan de una salud envidiable.

Tabla 3. Composición de la Cámara de Diputados 1993-2018.

\begin{tabular}{|l|c|c|c|c|c|c|}
\hline \multicolumn{1}{|c|}{ Partido } & $\mathbf{1 9 9 3}$ & $\mathbf{1 9 9 8}$ & $\mathbf{2 0 0 3}$ & $\mathbf{2 0 0 8}$ & $\mathbf{2 0 1 3}$ & $\mathbf{2 0 1 8}$ \\
\hline Asociación Nacional Republicana (ANR) & 38 & 45 & 37 & 30 & 44 & 42 \\
\hline Partido Liberal Radical Auténtico (PLRA) & 33 & 26 & 21 & 27 & 27 & 30 \\
\hline Partido Encuentro Nacional (PEN) & 7 & 7 & & & 2 & 2 \\
\hline Partido Revolucionario Febrerista (PRF) & 2 & & & & & \\
\hline Unión Nacional de Ciudadanos Eticos (Unace) & & & 10 & 15 & 2 & \\
\hline Partido Patria Querida (PPQ) & & & 10 & 3 & 1 & 3 \\
\hline Partido País Solidario (PPS) & & 2 & 2 & & & \\
\hline Movimiento Popular Tekojoja (MPT) & & & & 1 & & \\
\hline Partido Democrático Progresista (PDP) & & & & 2 & & \\
\hline Alianza Patriótica para el Cambio (APC) & & & & 1 & & \\
\hline Alianza Departamental Boquerón (ADB) & & & & & 2 & \\
\hline Avanza Pais (AP) & & & & & 1 & \\
\hline Alianza Pasión Chaqueña (APCh) & & & & & 1 & \\
\hline Frente Guasú (FG) & & & & & & 2 \\
\hline Hagamos & & & & & & 1 \\
\hline Cruzada Nacional & $\mathbf{8 0}$ & $\mathbf{8 0}$ & $\mathbf{8 0}$ & $\mathbf{8 0}$ & $\mathbf{8 0}$ & $\mathbf{8 0}$ \\
\hline Total
\end{tabular}

Fuente: elaboración propia a partir del TSJE (2018) y Cerna y Solís (2018, p. 368).

En cuanto a la Cámara de Senadores las circunstancias son algo diferentes porque, aunque la ANR y el PLRA son fuerzas predominantes que controlan en promedio dos de cada tres escaños, la fragmentación en este cuerpo legislativo ha sido históricamente más elevada (Cerna y Solís, 2018, p. 366). Esta tendencia ha vuelto a ser confirmada en esta elección, en la que los partidos que han perdido terreno, traducido en escaños, han sido la ANR, Unace y el PDP, gracias a lo cual se han visto beneficiados los partidos 
de nueva creación — Hagamos y Cruzada Nacional—, así como también el Frente Guasú (FG) y el Partido Patria Querida (PPQ), el cual ha recuperado su fuerza electoral perdida en los comicios de 2013 cuando se quedó sin representación en esta Cámara.

Tabla 4. Composición de la Cámara de Senadores 1993-2018.

\begin{tabular}{|l|c|c|c|c|c|c|}
\hline \multicolumn{1}{|c|}{ Partido } & $\mathbf{1 9 9 3}$ & $\mathbf{1 9 9 8}$ & $\mathbf{2 0 0 3}$ & $\mathbf{2 0 0 8}$ & $\mathbf{2 0 1 3}$ & $\mathbf{2 0 1 8}$ \\
\hline Asociación Nacional Republicana (ANR) & 20 & 24 & 16 & 15 & 20 & 17 \\
\hline Partido Liberal Radical Auténtico (PLRA) & 17 & 13 & 12 & 14 & 13 & 13 \\
\hline Partido Encuentro Nacional (PEN) & 7 & 7 & 1 & & 1 & \\
\hline Partido Revolucionario Febrerista (PRF) & 1 & & & & & \\
\hline Partido Blanco (PB) & & 1 & & & & \\
\hline Unión Nacional de Ciudadanos Éticos (Unace) & & & 7 & 9 & 2 & 1 \\
\hline Partido Patria Querida (PPQ) & & & 7 & 4 & & 3 \\
\hline Partido País Solidario (PPS) & & 2 & 1 & & \\
\hline Movimiento Popular Tekojoja (MPT) & & & & 1 & 3 & 2 \\
\hline Partido Democrático Progresista (PDP) & & & & & 1 & \\
\hline Avanza Pais (AP) & & & & & 5 & 6 \\
\hline Frente Guasú (FG) & & & & & & 2 \\
\hline Hagamos & & & & & & 1 \\
\hline Cruzada Nacional & $\mathbf{4 5}$ & $\mathbf{4 5}$ & $\mathbf{4 5}$ & $\mathbf{4 5}$ & $\mathbf{4 5}$ & $\mathbf{4 5}$ \\
\hline Total & & & & \\
\hline
\end{tabular}

[274 ] Fuente: elaboración propia a partir del TSJE (2018) y Cerna y Solís (2018, p. 368).

\subsection{Elecciones para las gobernaciones}

Si bien este tipo de elecciones no gozan de la relevancia que las dos anteriores, estas no son menos importantes pues, como sostienen Cerna y Solís (2017), en ellas se pueden distinguir de manera más fehaciente los resortes de los principales partidos políticos del país. Para estos autores, si bien este nivel de gobierno no tiene el peso de relevancia política que pudiera tener en países como México o Brasil, no se puede desestimar puesto que es en esta arena en la que principalmente se miden las maquinarias electorales de los grandes partidos (Alcántara, 2004).

Si se toma como antecedente que la ANR ha sido el partido que ha dominado esta arena de competencia desde que hay elecciones dentro de los cánones democráticos y que nunca ha dejado de gobernar a más de la mitad de los territorios del país (Cerna y Solís, 2017), esta elección ha confirmado esta tendencia, puesto que, de las diecisiete gobernaciones en disputa, los colorados se impusieron en trece de ellas, en comparación con las doce obtenidas cinco años atrás (Acuerdo y Sentencia 17/2008). En 
perspectiva comparada, este resultado solo es superado por el obtenido por el propio partido hace veinte años, cuando ganó catorce de las diecisiete gobernaciones del país (Cerna y Solís, 2017). En suma, esto revela, en buena medida, el arraigo territorial de este partido que encuentra en las «seccionales» creadas por Alfredo Stroessner el resorte electoral más efectivo para hilvanar triunfos en la mayor parte del territorio.

Lo más destacado en cuanto a esta arena de competencia en este último proceso electoral ha sido el triunfo del coloradismo en el principal bastión de los liberales, el departamento de Central, en el que se impuso el candidato cartista Hugo Javier González con un margen de catorce mil votos (Última Hora, 2018, abril 22). La geografía política tras las elecciones del 22 abril confirma el poderío de la ANR en los departamentos de Guairá, Caazapá, Itapúa, Paraguarí, Canindeyú y Alto Paraguay que se constituyen en bastiones hasta ahora inexpugnables, mientras que la fuerza del PLRA se ha achicado para remitirse solamente al fronterizo departamento de Amambay (Cerna y Solís, 2017, pp. 163-164) y las terceras fuerzas simplemente no existen en este ámbito (véase tabla 5).

Tabla 5. Distribución de las gobernaciones, 1998-2018.

\begin{tabular}{|l|l|l|l|l|l|}
\hline & \multicolumn{1}{|c|}{$\mathbf{1 9 9 8}$} & \multicolumn{1}{|c|}{$\mathbf{2 0 0 3}$} & \multicolumn{1}{|c|}{$\mathbf{2 0 0 8}$} & \multicolumn{1}{c|}{$\mathbf{2 0 1 3}$} & \multicolumn{1}{|c|}{$\mathbf{}$} \\
\hline Departamento & Ganador & Ganador & Ganador & Ganador & Ganador \\
\hline Concepción & PLRA-PEN & PLRA & PLRA & ANR & PLRA \\
\hline San Pedro & ANR & ANR & PLRA & ANR & ANR \\
\hline Cordillera & ANR & ANR & PLRA & PLRA & PLRA \\
\hline Guairá & ANR & ANR & ANR & ANR & ANR \\
\hline Caaguazú & ANR & PLRA & PLRA & ANR & ANR \\
\hline Caazapá & ANR & ANR & ANR & ANR & ANR \\
\hline Itapúa & ANR & ANR & ANR & ANR & ANR \\
\hline Misiones & ANR & ANR & PLRA & ANR & ANR \\
\hline Paraguarí & ANR & ANR & ANR & ANR & ANR \\
\hline Alto Paraná & ANR & PLRA & ANR & ANR & ANR \\
\hline Central & PLRA & PLRA & PLRA & PLRA & ANR \\
\hline Neembucú & ANR & ANR & ANR & PLRA & ANR \\
\hline Amambay & PLRA & PLRA & PLRA & PLRA & PLRA \\
\hline Canindeyú & ANR & ANR & ANR & ANR & ANR \\
\hline Pdte. Hayes & ANR & ANR & ANR & APC & ANR \\
\hline Alto Py & ANR & ANR & ANR & ANR & ANR \\
\hline Boquerón & PLRA-PEN & ANR & ADB & ANR & ANR \\
\hline
\end{tabular}

Fuente: elaboración propia a partir del TSJE (2018) y Cerna y Solís (2017, pp. 163-164). Las filas en gris resaltan los bastiones electorales de los respectivos partidos. 


\subsection{Número efectivo de partidos}

Al correr la famosa fórmula de Markku Laakso y Rein Taagepera (1979, pp. 3 y ss.) para las elecciones de presidente, diputados y senadores, se encuentra que, salvo en la elección presidencial, continúa la tendencia incremental en este indicador, lo que revelaría que el sistema de partidos se ha ido fragmentando cada vez más y ha ido transitando de la predominancia de un solo partido al bipartidismo, al pluralismo moderado. No obstante, como se ha visto hasta acá, la aparición de nuevos partidos en ningún caso hace sombra a los partidos tradicionales, que a pesar de todo continúan acaparando el tablero electoral del país (véase tabla 6).

Tabla 6. Evolución del número efectivo de partidos (NEP), 1993-2018.

\begin{tabular}{|l|c|c|c|c|c|c|}
\hline & $\mathbf{1 9 9 3}$ & $\mathbf{1 9 9 8}$ & $\mathbf{2 0 0 3}$ & $\mathbf{2 0 0 8}$ & $\mathbf{2 0 1 3}$ & $\mathbf{2 0 1 8}$ \\
\hline Presidente & 1.68 & 2.18 & 3.91 & 3.34 & 2.91 & 2.50 \\
\hline Diputados & 1.74 & 2.19 & 4.21 & 4.39 & 4.32 & 5.77 \\
\hline Senadores & & 2.25 & 4.75 & 4.66 & 4.97 & 6.42 \\
\hline
\end{tabular}

Fuente: elaboración propia a partir de Cerna y Solís $(2018$, p. 366).

Por otra parte, al capturar el número efectivo de partidos parlamentarios (NEPp) se puede dar cuenta de que este indicador ha oscilado entre el bipartidismo y un discreto pluralismo de tres partidos efectivos (véase tabla 7). Ahora bien, si para esta última elección se dividen las bancadas de la ANR en los dos bloques antagónicos: Añeteté y Honor Colorado, el NEPp aumenta significativamente. Se ha querido resaltar este indicador puesto que se aproxima más a la realidad política del país, y aunque se ubica en el campo de lo que Giovanni Sartori (1976) define como pluralismo moderado, lo cierto es que el presidente Abdo Benítez no cuenta por sí mismo con la mayoría legislativa o la disciplina de su partido (Última Hora, 2018, julio 9), por lo que es probable que encuentre dificultades para tramitar exitosamente su agenda política y que su relación con el órgano legislativo llegue a ser compleja.

Tabla 7. Evolución del número efectivo de partidos parlamentario, 1993-2018.

\begin{tabular}{|l|c|c|c|c|c|c|c|}
\hline & $\mathbf{1 9 9 3}$ & $\mathbf{1 9 9 8}$ & $\mathbf{2 0 0 3}$ & $\mathbf{2 0 0 8}$ & $\mathbf{2 0 1 3}$ & $\mathbf{2 0 1 8}$ & $\mathbf{2 0 1 8}^{\text {* }}$ \\
\hline Diputados & 2.47 & 2.32 & 3.17 & 3.42 & 2.38 & 2.38 & 3.55 \\
\hline Senadores & 2.74 & 2.54 & 4.02 & 3.88 & 3.32 & 3.94 & 5.43 \\
\hline
\end{tabular}

Fuente: elaboración propia a partir de Cerna y Solís (2018). 


\subsection{Concentración y competitividad electoral}

Estos indicadores capturan el aglutinamiento del voto de los ciudadanos entre las dos fuerzas más votadas y qué tan disputadas son las elecciones. En el primer caso, se trata de una adición de las preferencias en la que valores más cercanos a cien indican mayor concentración, mientras que en el segundo a una sustracción en la que valores más próximos a cero hacen referencia a una elección más competida (véase tabla 8). En el contexto de las elecciones presidenciales paraguayas, con excepción de la elección de 2003 en la que candidatos de terceros partidos arrebataron una buena cantidad de votos a los tradicionales ANR y PLRA, en general ha existido una concentración alta que se ha venido acentuando en las dos últimas elecciones, en las que tanto colorados como liberales aglutinan ocho o nueve de cada diez preferencias electorales.

Por su parte, al hablar de la competitividad de las elecciones, esta última elección ha sido la más competida en la historia de los comicios democráticos del país, ya que hasta antes de estas elecciones la tendencia había sido más bien de una competitividad moderada en la que los ganadores obtenían sus victorias con holgura. En el caso de esta última elección, la diferencia fue de apenas 96 mil votos, distancia no prevista por las casas encuestadoras que una vez más erraron drásticamente en el resultado e invita a una reflexión profunda sobre su seriedad en ese país sudamericano (BBC, 2018, abril 23).

Tabla 8. Concentración y competitividad electoral de las elecciones presidenciales, 1993-2018.

\begin{tabular}{|l|c|c|c|c|c|c|}
\hline & $\mathbf{1 9 9 3}$ & $\mathbf{1 9 9 8}$ & $\mathbf{2 0 0 3}$ & $\mathbf{2 0 0 8}$ & $\mathbf{2 0 1 3}$ & $\mathbf{2 0 1 8}$ \\
\hline Concentración & 74.98 & 96.4 & 61.1 & 71.6 & 82.7 & 89.16 \\
\hline Competitividad & 8.58 & 11.2 & 13.1 & 10.2 & 8.9 & 3.68 \\
\hline
\end{tabular}

Fuente: elaboración propia a partir del TSJE (2018) y Cerna y Solís (2018).

\subsection{Volatilidad agregada}

Este indicador, que refleja los cambios en las preferencias netas de una elección a otra, muestra datos interesantes con relación a la serie que se venían presentando desde 1993. En ese sentido, la elección de 2018 evidencia una menor variación en la volatilidad agregada, lo que hasta hace poco tiempo se veía complicado debido al comportamiento del electorado paraguayo de cambiar notoriamente sus preferencias (Cerna y Solís, 2018). 
Este deslizamiento a lo que sería una volatilidad relativamente baja, sobre todo en la elección presidencial y del Senado vendría a confirmar el afianzamiento de los grandes partidos paraguayos que han logrado conservar, de momento, la fidelidad de buena parte de su electorado.

Tabla 9. Volatilidad agregada de las elecciones paraguayas, 1993-2018.

\begin{tabular}{|l|c|c|c|c|c|c|}
\hline & $\mathbf{1 9 9 3}$ & $\mathbf{1 9 9 8}$ & $\mathbf{2 0 0 3}$ & $\mathbf{2 0 0 8}$ & $\mathbf{2 0 1 3}$ & $\mathbf{2 0 1 8}$ \\
\hline Presidente & 32.95 & 23.75 & 35.05 & 25.35 & 25.40 & 9.55 \\
\hline Diputados & 33.33 & 17.75 & 35.95 & 15.85 & 19.45 & 17.54 \\
\hline Senadores & & 17.10 & 35.95 & 13.85 & 29.65 & 12.60 \\
\hline
\end{tabular}

Fuente: elaboración propia a partir del TSJE (2018) y Cerna y Solís (2018, p. 366).

\subsection{Nacionalización de partidos}

Con este indicador se busca medir la homogeneidad de apoyos que recibe un partido político en la totalidad de territorios que conforman un país (Jones y Mainwaring, 2003). En el caso paraguayo, la tabla 10 indica la asimetría que existe entre los partidos tradicionales que están altamente implantados en el territorio, frente a lo escasamente territorializados que se

[278] encuentran los demás partidos. Para la elección de 2018, se ha incluido en la medición de este indicador a nuevos partidos que han adquirido alguna relevancia, ya sea por su capacidad de obtener escaños, como Cruzada Nacional o Hagamos, o porque han mostrado más consistencia que otros partidos para presentar candidatos propios a las elecciones para gobernador en diferentes departamentos, como lo son el Movimiento Nacional de Artistas del Paraguay y el Partido Verde de Paraguay, o bien porque suponen una notoria novedad en el escenario político como el Movimiento Político Indígena Plurinacional.

Lo interesante de este ejercicio es que se confirma la estabilidad en cuanto a la nacionalización de la ANR, el PLRA y la Unace, mientras que se destaca que a pesar de no haber alcanzado representación política alguna, el Partido Verde de Paraguay cuenta con una estructura y homogeneidad del voto más sólida que el Frente Guasú, que es el partido más nacionalizado entre las organizaciones de izquierda, y que partidos como Cruzada Nacional, Hagamos y el Movimiento Político Indígena Plurinacional están claramente anclados en territorios específicos por lo que sus apoyos tienden a ser muy heterogéneos a lo largo y ancho de la geografía nacional. 
Fricción, (re)concentración y afianzamiento conservador tras las elecciones de 2018...

Tabla 10. Índice de nacionalización de partidos, 1998-2018.

\begin{tabular}{|l|c|c|c|c|c|}
\multicolumn{1}{|c|}{ Partido } & 1998 & $\mathbf{2 0 0 3}$ & $\mathbf{2 0 0 8}$ & $\mathbf{2 0 1 3}$ & $\mathbf{2 0 1 8}$ \\
\hline Asociación Nacional Republicana (ANR) & 0.94338434 & $\mathbf{0 . 8 8 8 7 3 7 3 2}$ & $\mathbf{0 . 9 1 6 5 8 2 5 6}$ & $\mathbf{0 . 9 4 3 8 6 4 1 6}$ & $\mathbf{0 . 9 2 1 4 0 4 7 4}$ \\
\hline Partido Liberal Radical Auténtico (PLRA) & 0.93564543 & 0.75260321 & 0.85513403 & 0.88319005 & 0.89415304 \\
\hline Unión Nacional de Ciudadanos Éticos (Unace) & & 0.70074122 & 0.74086617 & 0.49557244 & 0.49387238 \\
\hline Partido Patria Querida (PPQ) & & 0.63948575 & & & \\
\hline Partido Encuentro Nacional (PEN) & & 0.12493081 & & & \\
\hline Movimiento Popular Tekojoja (MPT) & & 0.31066545 & & \\
\hline Frente Guasú (FG) & & & 0.51809104 & 0.20043893 \\
\hline Partido Verde & & & & 0.37262375 \\
\hline Cruzada & & & & & 0.06667157 \\
\hline Hagamos & & & & & 0.058824 \\
\hline Artistas & & & & 0.2072223 \\
\hline Plurinacional & & & & 0.058824 \\
\hline
\end{tabular}

Fuente: elaboración propia a partir del TSJE (2018) y Cerna y Solís (2017, p. 178).

Otros datos no menores en cuanto a las elecciones generales en Paraguay son las denuncias de algunos apoderados del PLRA y de varios partidos minoritarios sobre irregularidades en el conteo de los votos y en la transcripción de las actas electorales al conteo preliminar del TSJE. Estas denuncias, en general, fueron desestimadas por el mismo TSJE (ABC Color, 2018, abril 27). En un contexto político crispado y con unos resultados preliminares tan estrechos en los cargos del Poder Ejecutivo, dichas denuncias tuvieron eco en el ámbito internacional, precisamente porque este país sudamericano se ha caracterizado por la baja credibilidad institucional y la corrupción política imperante en el país (Infobae, 2018, agosto 1).

\section{Conclusiones. Escenarios futuros}

La crispación política y social que se suscitó previamente a las elecciones de 2018 con el debate sobre la habilitación de la reelección presidencial promovida por el entonces presidente Cartes no solo abrió las aguas de la confrontación por la candidatura en el oficialista Partido Colorado, sino que ha abierto todo un frente de guerra entre familias coloradas que hacen previsible que las huestes más afines al expresidente Cartes se constituyan en el bloque opositor más férreo al que hará frente el estrenado presidente Mario Abdo Benítez. La retirada de la facción de Honor Colorado de la ceremonia de inauguración del mandato presidencial del nuevo gobernante es toda una declaración de intenciones. 
La previsible indisciplina de la bancada colorada da al traste a los más que buenos resultados que obtuvo la organización en la pasada elección en la que ha recobrado el vigor perdido un par de décadas atrás. El partido ha sido capaz de retener la presidencia, la mayoría en el Congreso y el control de las gobernaciones departamentales; sin embargo, esto parece quedar en segundo plano por las confrontaciones que existen entre facciones que hacen poco probable que el presidente Abdo logre concretar su deseo de convocar a una Asamblea Constituyente para reformar la carta magna tal y como lo prometió en campaña. El horno no está para bollos y el mandatario deberá cuidar los equilibrios entre poderes para garantizar la gobernabilidad en un sistema político en el que la evidencia empírica demuestra que cuando el presidente no cuenta con la disciplina de su partido aumentan las probabilidades de ser al menos amenazado con la figura del juicio político (Cerna y Solís 2018, pp. 359-360).

El proceso electoral deja, además, la reafirmación de un sistema de partidos, que a diferencia de la mayoría en la región tiende a consolidar a los partidos tradicionales que aglutinan nueve de cada diez preferencias electorales y que son auténticas maquinarias electorales que se reparten la [280 ] casi totalidad del poder territorial, dejando muy poco espacio para terceras fuerzas que, en cualquier caso, solo tienen una presencia heterogénea en los departamentos más urbanizados. Esto debe mirarse con mayor detenimiento, pues la mayoría de estos pequeños partidos no presentan significativas diferencias en ideología y valores en relación con la ANR y el PLRA, por lo que se presume que es muy poco probable que en los próximos años existan avances en otro tipo de agendas más progresistas, como la de la despenalización del aborto, la legalización del consumo recreativo de la marihuana o el matrimonio igualitario.

Los sesgos morales y religiosos continúan siendo muy fuertes en la sociedad paraguaya, y así lo reflejan sus políticos, que como el presidente Abdo remiten su negativa a supuestos mandatos de la Biblia. La izquierda, en ese sentido, no es sustancialmente ajena a esta visión conservadora. Si el principal referente de este campo ideológico es un exobispo como Fernando Lugo, queda poco espacio para abrigar esperanzas en el corto y mediano plazo para que la ampliación de derechos, como los antes mencionados, encuentren cabida en la agenda política del país. 
Fricción, (re)concentración y afianzamiento conservador tras las elecciones de 2018...

\section{Referencias bibliográficas}

1. ABC Color. (2017, septiembre 28). El combo mafioso perfecto: «listas sábanas» más «fueros». Recuperado de http://www.abc.com.py/edicion-impresa/editorial/elcombo-mafioso-perfecto-listas-sabana-mas-fueros-1635832.html

2. ABC Color. (2018, enero 22). Alegre inicia campaña con alusión al pasado stronista de Abdo Benítez. Recuperado de http://www.abc.com.py/edicionimpresa/politica/alegre-inicia-campana-con-alusion-al-pasado-stronista-de-abdobenitez-1668546.html

3. ABC Color. (2018, febrero 17). «Efraín, cuidá a tu familia». Recuperado de http://www.abc.com.py/nacionales/efrain-cuida-tu-familia-1676030.html

4. ABC Color. (2018, marzo 27). Marito promete coloradizar al funcionariado público. Recuperado de http://www.abc.com.py/edicion-impresa/editorial/maritopromete-coloradizar-al-funcionariado-publico-1687721.html

5. ABC Color. (2018, abril 5). Alegre firma compromiso con la Educación. Recuperado de http://www.abc.com.py/nacionales/alegre-firma-compromiso-por-laeducacion-1690250.html

6. ABC Color. (2018, abril 27). Suman denuncias por irregularidades en actas. Recuperado de http://www.abc.com.py/nacionales/suman-denuncias-porirregularidades-en-las-actas-1697511.html

7. Abente, Diego. (2012). Estabilidad y calidad de la democracia en Paraguay. América Latina Hoy, 60, pp. 43-66.

8. Agencia AFP. (2018, marzo, 28). Fabricio Alvarado, el evangélico cantante que aspira a la presidencia de Costa Rica. El Heraldo. Recuperado de https://www. elheraldo.hn/mundo/1 164384-466/fabricio-alvarado-el-evang\%C3\%A9lico-cantanteque-aspira-a-la-presidencia-de-costa

9. Alvarenga, Lucho. (2006, diciembre 31). El 2006: año perdido por la ambición de poder de Nicanor. Última Hora. Recuperado de https://www.ultimahora.com/el2006-ano-perdido-la-ambicion-poder-nicanor-n12274.html

10. Alcántara, Manuel. (2004). ¿Instituciones o máquinas ideológicas? Origen, programa e institucionalización de los partidos políticos latinoamericanos. Barcelona: ICPS.

11. Alcántara, Manuel y Tagina, María Laura. (2013). Procesos políticos y electorales en América Latina (2010-2013). Buenos Aires: Eudeba.

12. Alcántara, Manuel, Tagina, María Laura y Buquet, Daniel. (2018). Elecciones y partidos en América Latina en el cambio de ciclo. Madrid: Centro de Investigaciones Sociológicas.

13. BBC. (2018, abril 23). Elecciones en Paraguay: Mario Abdo gana la presidencia en una reñida jornada electoral. Recuperado de https://www.bbc.com/mundo/ noticias-america-latina-43860647 
14. Bedinelli, Talita; Marcos, Ana y Lafuente, Javier. (2018, abril 13). La fe evangélica abraza las urnas en América Latina. El País. Recuperado de https://elpais. com/internacional/2018/04/13/america/1523653238_321594.html

15. Brenes, Danny. (2018, febrero 10). Conquista evangélica: de la fe al poder. La Nación. Recuperado de https://www.nacion.com/revista-dominical/conquistaevangelica-de-la-fe-al-poder/ERK6Z6LL6ZA6VKA52ODO2G7KMM/story/

16. Carneri, Santi. (2017, abril 7). Fracasa un primer intento en Paraguay para cerrar la crisis política. El País. Recuperado de https://elpais.com/internacional/2017/04/07/ america/1491528457_280153.html

17. Cerna Villagra, Sarah Patricia. (2017, abril 3). Tentación reeleccionista y democracia en Ilamas. Estudios de Política Exterior. Recuperado de https://www. politicaexterior.com/latinoamerica-analisis/tentacion-reeleccionista-y-democracia-enIlamas/

18. Cerna Villagra, Sarah Patricia y Solís Delgadillo, Juan Mario. (2012). La crisis institucional paraguaya a la luz de las élites parlamentarias. Boletín Élites Parlamentarias Latinoamericanas, 42. Recuperado de https://gredos.usal.es/jspui/ bitstream/10366/122528/1/boletin_elites_42_2012.pdf

19. Cerna Villagra, Sarah Patricia y Solís Delgadillo, Juan Mario. (2017). Los resortes colorados del poder: nacionalización de los partidos y el sistema de partidos paraguayo (1998-2013). Colombia Internacional, 91, pp. 151-184. https://doi. org/10.7440/colombiaint91.2017.05

20. Cerna Villagra, Sarah Patricia y Solís Delgadillo, Juan Mario. (2018). Paraguay: entre el pluralismo moderado y el predominio de los actores tradicionales. En: Alcántara Manuel; Buquet, Daniel y Tagina, María Laura (eds.). Elecciones y partidos en América Latina en el cambio de ciclo (pp. 353-376). Madrid: CIS.

21. Corona, Sonia. (2018, julio 12). Los evangélicos se aferran a López Obrador. El País. Recuperado de https://elpais.com/internacional/2018/07/09/ mexico/1531161540_362658.html

22. Corrales, Javier. (2018, enero 19) Un matrimonio perfecto: evangélicos y conservadores en América Latina. The New York Times. Recuperado de https://www. nytimes.com/es/2018/01/19/opinion-evangelicos-conservadores-america-latinacorrales/

23. Díaz Valinotti, Elvio. (2011, abril 28). Hace 5 años, Lugo luchaba contra reelección. $A B C$ Color. Recuperado de http://www.abc.com.py/nacionales/hace-5anos-lugo-luchaba-contra-reeleccion-250418.html

24. Došek, Tomáš; Pérez Talia, Marcos y Duarte Recalde, Liliana Rocío. (2016). Elecciones municipales en Paraguay de 2015: cambios simbólicos y continuidades sustanciales. Revista Uruguaya de Ciencia Política, 25 (1), pp. 137-156.

25. Duarte, Rocío. (2012). Variaciones en el comportamiento electoral en Paraguay. América Latina Hoy, 60, pp. 117-138. 
Fricción, (re)concentración y afianzamiento conservador tras las elecciones de 2018...

26. Duarte, Rocío. (2013). Paraguay: interrupción al proceso de consolidación de la democracia. Revista de Ciencia Política, 33 (1), pp. 303-324. https://doi. org/10.4067/S0718-090X2013000100015

27. Filártiga, Camilo. (2018). Sistema electoral paraguayo: consideraciones para una reforma constitucional. Asunción: Centro de Estudios Judiciales.

28. González Tule, Luis A. (2017) Los sistemas electorales. En: Martí i Puig, Salvador; Solís Delgadillo, Juan Mario y Sánchez, Francisco (eds.). Curso de Ciencia Política (pp. 491-517). México, D. F.: Senado de la República.

29. Infobae. (2018, agosto 1). Escándalo en Paraguay por denuncias de fraude en las últimas elecciones presidenciales. Recuperado de https://www.infobae.com/ america/america-latina/2018/08/01/escandalo-en-paraguay-por-denuncias-de-fraudeen-las-ultimas-elecciones-presidenciales/

30. Jones, Mark \& Mainwaring, Scott. (2003). The Nationalization of Parties and Party Systems. An empiricak Measure and an Application to the Americas. Party Politics, 9 (2), pp. 139-166. https://doi.org/10.1177/13540688030092002

31. Laakso, Markku \& Taagepera, Rein. (1979). Effective Number of Parties: A Measure with Application to West Europe. Comparative Political Studies, 12, pp. 3-27. https://doi.org/10.1177/001041407901200101

32. Lafuente, Javier. (2018, octubre 8). Los evangélicos se convierten a Bolsonaro. El País. Recuperado de https://elpais.com/internacional/2018/10/07/ america/1538930780_735803.html

33. La Nación. (2017, julio 26). Abdo Benítez, Montanaro, Godoy Jiménez y Jacquet: 30 años de un capítulo negro en la ANR. Recuperado de https://www. lanacion.com.py/politica/2017/07/26/abdo-benitez-montarano-godoy-gimenez-yjacquet-30-anos-de-un-capitulo-negro-en-la-anr/

34. La Nación. (2017, diciembre 18). La dupla opositora en el 2018 será Efraín Alegre-Leo Rubín. Recuperado de https://www.lanacion.com.py/politica_edicion_ impresa/2017/12/18/la-dupla-opositora-en-el-2018-sera-efrain-alegre-leo-rubin/

35. La Nación. (2018, febrero 11). Alegre salpicado por varios hechos de corrupción. Recuperado de https://www.lanacion.com.py/destacado_edicion impresa/2018/02/11/alegre-un-candidato-salpicado-por-varios-hechos-de-corrupcion/

36. La Nación. (2018, abril 7). Evangélicos instan a votar por candidatos pro vida y familia. La Nación. Recuperado de https://www.lanacion.com.py/politica_edicion_ impresa/2018/04/07/evangelicos-instan-a-votar-por-candidatos-pro-vida-y-familia/

37. Lissardy, Gerardo. (2017). Por qué 2017 puede ser la clave en el giro hacia la derecha de América Latina. BBC News. Recuperado de https://www.bbc.com/mundo/ noticias-america-latina-38493148

38. Lissardy, Gerardo. (2018, abril 17). «La fuerza política más nueva»: cómo los evangélicos emergen en el mapa de poder en América Latina. BBC News. Recuperado de https://www.bbc.com/mundo/noticias-america-latina-43706779 
39. Londoño, Ernesto; Bonnefoy, Pascale y Politi, Daniel. (2017, diciembre 19). La victoria de Piñera refuerza el giro a la derecha de América Latina. The New York Times. Recuperado de https://www.nytimes.com/es/2017/12/19/chile-pinera-americalatina-derecha/

40. Núñez, Leticia. (2018, julio 19). Se interrumpe el giro la derecha en América Latina. Alnavío. Noticias de ida y vuelta. Recuperado de https://alnavio.com/ noticia/14400/actualidad/se-interrumpe-el-giro-a-la-derecha-en-america-latina.html

41. Paraguay. Tribunal Superior de Justicia Electoral. (2018) Acuerdo y Sentencia 17. (22 de abril de 2018). Recuperado de https://tsje.gov.py/static/ups/docs/ archivos/2018/mayo/acuerdo-sentencia-17-2018-completo.pdf

42. Paraguay.com. (2018, febrero 26). Alianza Ganar lanza campaña: «Debemos cambiar este modelo de 70 años». Recuperado de http://www.paraguay.com/ nacionales/alianza-ganar-lanza-campana-debemos-cambiar-este-modelo-de-70anos-174711

43. Pérez-Liñán, Aníbal. (2009). Juicio político al presidente y nueva inestabilidad política en América Latina. México, D. F.: FCE.

44. Pérez-Liñán, Aníbal. (2014). A Two-Level Theory of Presidential Instability. Latin America Politics \& Society, 56 (1), pp. 34-54. https://doi.org/10.1111/j.15482456.2014.00220.x

45. Pérez-Liñán, Aníbal \& Polga-Hecimovich, John. (2017). Explaining Military Coups and Impeachments in Latin America. Democratization, 24 (5), pp. 839-858.

[284 ] https://doi.org/10.1080/13510347.2016.1251905

46. Pérez Talia, Marcos. (2018, junio 13). Paraguay en su eterno laberinto de gobernabilidad. Estudios de Política Exterior. Recuperado de https://www. politicaexterior.com/latinoamerica-analisis/paraguay-eterno-laberinto-gobernabilidad/

47. Quintana Cataño, María del Mar. (2018, octubre 28). ¿Está América Latina dando un giro hacia la extrema derecha? El Tiempo. Recuperado de https://www. eltiempo.com/mundo/latinoamerica/esta-america-latina-dando-un-giro-hacia-laextrema-derecha-285796

48. Sartori, Giovanni. (1976). Partidos y sistemas de partidos. Madrid: Alianza.

49. Solís Delgadillo, Juan Mario y Cerna Villagra, Sarah Patricia. (2013). De la Ilanura al palacio: la restauración de la pax colorada en Paraguay. En: Alcántara, Manuel y Tagina, María Laura (eds.). Procesos políticos y electorales en América Latina (2010-2013) (pp. 401-430). Buenos Aires: Eudeba.

50. Solís Delgadillo, Juan Mario y Cerna Villagra, Sarah Patricia (2014). El darwinismo guaraní: evolución y extinción de las especies políticas paraguayas. Revista Latinoamericana de Política Comparada, 8, pp. 95-117.

51. Solís Delgadillo, Juan Mario y Cerna Villagra, Sarah Patricia. (2016). De la mitra episcopal a la banda presidencial: la elección de Fernando Lugo y la caída del Partido Colorado en Paraguay. En: Querido, Leandro y Domínguez Sardou, Fernando 
Fricción, (re)concentración y afianzamiento conservador tras las elecciones de 2018...

(coords.). Elecciones en Latinoamérica 1985-2015. 30 años de transformación democrática (pp. 119-129). Buenos Aires: Dunken.

52. Telefuturo. (2017, mayo 10). Diferencias entre Santiago Peña y Marito Abdo Benítez. Recuperado de http://telefuturo.com.py/noticia/21782-Diferencias-entreSantiago-Pea-y-Marito-Abdo-Benitez

53. Tribunal Superior de Justicia Electoral (TSJE). (2018). Elecciones generales. Recuperado de https://tsje.gov.py/elecciones-generales-2018.html

54. Uharte, Luis. (2012). El proceso de democratización paraguayo: avances y resistencias. América Latina Hoy, 60, pp. 17-42.

55. Última Hora. (2017, septiembre 5). Justicia Electoral ordena al PLRA excluir a Santiago Peña de su padrón. Recuperado de https://www.ultimahora.com/justiciaelectoral-ordena-al-plra-excluir-santiago-pena-padron-n1 106058.html

56. Última Hora. (2018, febrero 18). Efraín responsabiliza a Cartes de la seguridad de su familia. Recuperado de https://www.ultimahora.com/efrain-responsabilizacartes-la-seguridad-su-familia-n1134279.html

57. Última Hora. (2018, marzo 28a). Para Marito hijos de madres solteras deben ir al cuartel. Recuperado de https://www.ultimahora.com/para-marito-hijos-madressolteras-deben-ir-al-cuartel-n1140244.html

58. Última Hora. (2018, marzo 28b). Serpaj rechaza expresiones de Marito sobre hijos de madres solteras. Recuperado de https://www.ultimahora.com/serpaj-rechazaexpresiones-marito-hijos-madres-solteras-n1140302.html

59. Última Hora. (2018, abril 3). Marito propone un plan estratégico de desarrollo nacional. Recuperado de https://www.ultimahora.com/marito-propone-un-planestrategico-desarrollo-nacional-12-puntos-n1140913.html

60. Última Hora. (2018, abril 15). Las propuestas de Marito y Efraín sobre desarrollo económico. Recuperado de https://www.ultimahora.com/las-propuestasmarito-y-efrain-desarrollo-economico-n1143006.html

61. Última Hora (2018, abril 22). Hugo Javier rompe hegemonía liberal en Central. Recuperado de https://www.ultimahora.com/hugo-javier-rompe-hegemonialiberal-central-n1144172.html

62. Última Hora. (2018, abril 23). Misión de OEA desaprueba bocas de urna y encuestas. Recuperado de https://www.ultimahora.com/mision-oea-desapruebabocas-urna-y-encuestas-n1144283.html

63. Última Hora (2018, julio 9). Abdo iniciará gobierno con fuerzas divididas en el Congreso. Recuperado de https://www.ultimahora.com/abdo-iniciara-gobiernofuerzas-divididas-el-congreso-n1304264.html 